\title{
CIÊNCIA, TECNOLOGIA E INOVAÇÃO EM NOTÍCIA NO VALE DO PARAÍBA
}

\section{SCIENCE, TECHNOLOGY AND INNOVATION IN NEWS AT VALE DO PARAÍBA}

\author{
Paula Carolina Rabelo Vinhas ${ }^{1}$ \\ Paulo Roxo Barja ${ }^{2}$
}

Resumo: Embora a região do Vale do Paraíba seja considerada um importante polo de pesquisa, tecnologia e inovação em nível nacional, é discreto o papel da imprensa local na difusão desses temas junto à comunidade. O presente trabalho consiste na avaliação da cobertura diária em Ciência, Tecnologia e Inovação (CT\&I), ao longo de um mês (dezembro de 2014), em dois periódicos (mídia impressa e internet) do Vale do Paraíba, "O Vale" e "Meon", com o objetivo principal de avaliar quais os temas priorizados pela imprensa local (de abrangência regional) na área de CT\&I. Para isso, e com o intuito de auxiliar a análise crítica da cobertura midiática desses temas, dividimos o material recolhido em três categorias: I) temas gerais; II) assunto; III) escala espacial.

Palavras-chave: divulgação científica; discurso jornalístico; CT\&I; Vale do Paraíba.

Abstract: Although the Vale do Paraíba region is considered an important center of research, technology and innovation at the national level, the role of the local media in the dissemination of these issues in the community is discrete. This study presents an evaluation of the daily coverage in Science, Technology and Innovation (ST\&I), over a month (December 2014), in two papers (print and internet) of the Vale do Paraíba, "O Vale" and "Meon", with the main objective to assess which topics were prioritized by the local press (regional coverage) in the ST\&I area. For this, and in order to assist the critical analysis of media coverage of these issues, we divide the collected material into three categories: I) general terms; II) matter; III) spatial scale.

Keywords: scientific divulgation; journalistic discourse; ST\&I; Vale do Paraiba.

\footnotetext{
${ }^{1}$ Graduada em Comunicação Social - Jornalismo - Universidade do Vale do Paraíba - UNIVAP, Brasil. E-mail: paulacvinhas@gmail.com.

${ }^{2}$ Doutor em Física pela Universidade Estadual de Campinas, Brasil. Professor da Universidade do Vale do Paraíba - UNIVAP, Brasil. E-mail: barja@univap.br.
} 


\section{INTRODUÇÃO: a importância da divulgação científica}

Quando falamos de difundir a ciência, há dois caminhos diferentes que podem ser seguidos: a divulgação científica e a comunicação científica. Por "difundir a ciência", tomamos a definição de Albagli (1996):

Difusão científica refere-se a 'todo e qualquer processo usado para a comunicação da informação científica e tecnológica'. Ou seja, a difusão científica pode ser orientada tanto para especialistas (neste caso, é sinônimo de disseminação científica), quanto para o público leigo em geral (aqui tem o mesmo significado de divulgação). (ALBAGLI, 1996, p. 397).

Entendemos, então, que a comunicação (ou disseminação) cientifica é realizada principalmente entre os próprios cientistas, especialistas em suas áreas, que compartilham e debatem suas pesquisas em revistas acadêmicas e eventos científicos; por outro lado, a divulgação científica é voltada ao público leigo, não alfabetizado no "vocabulário científico", e pode (deve) ocorrer nos diversos veículos da mídia.

De acordo com Silva, Arouca e Guimarães (2002), a divulgação científica mostra sua importância, hoje, a partir de três objetivos básicos: "1. afirmar o direito de cidadania com relação ao conjunto das questões científicas e tecnológicas; 2. despertar as vocações científicas nos jovens; 3. gerar parâmetros para a própria comunidade científica." (p.155). Desse modo, a popularização da ciência, obtida por meio de divulgação científica de boa qualidade, é necessária para a formação de cidadãos - e mesmo cientistas - mais críticos.

Na cobertura jornalística de atividades científicas, é usual partir do pressuposto de que ao público leigo interessam, principalmente, notícias que afetem, diretamente, suas vidas ou que gerem um grau de curiosidade ou fascínio. Lage (2001) elenca as quatro principais áreas de conteúdo presentes em matérias de divulgação científica: I) Medicina - com ênfase em epidemias, obesidade, câncer e AIDS; II) Cosmologia com a investigação do Universo; III) Biologia - com foco em ecologia e/ou genética; IV) Inteligência Artificial - matérias sobre desenvolvimento tecnológico, com perspectivas de aplicação prática.

Sendo São José dos Campos uma cidade considerada polo tecnológico, onde (por esta razão) haveria abundância de conteúdo científico para divulgação, bem como um bom número de especialistas acessíveis para entrevistas relativas a diversas áreas da ciência, buscamos, por meio deste trabalho, avaliar qual é o real conteúdo de CT\&I divulgado na mídia local, de abrangência, predominantemente, regional. Ressaltamos que o presente estudo faz parte de um trabalho mais amplo (Projeto Universal CNPq, aprovado no final de 2014), que pretende analisar a divulgação científica na imprensa do Vale do Paraíba, bem como suas consequências sociais. Ao longo do presente artigo, apresentaremos o panorama correspondente ao mês de dezembro de 2014, 
que apresenta, como peculiaridade, o fato de ter sido o período em que ocorreu o lançamento do satélite CBERS, uma parceria entre Brasil e China, com a participação substancial de pesquisadores do Instituto Nacional de Pesquisas Espaciais (INPE), com sede principal na cidade de São José dos Campos.

\section{METODOLOGIA}

Para a análise, foram coletadas as 25 matérias, publicadas em dezembro de 2014, nos jornais O Vale (jornal impresso, com publicação também online) e Meon (online), encontradas a partir da busca pelas palavras-chave "ciência", "inovação" e "tecnologia". A busca não se limitou à editoria de ciência dos veículos citados. O conjunto das matérias coletadas passou pelo programa Dtsearch, para contagem da incidência de palavras-chave.

Partindo dos resultados obtidos após processamento, efetuou-se a catalogação dos dados, de acordo com três eixos, a saber: I) termos gerais (Ciência, Desenvolvimento, Equipamento(s), Pesquisa, Programa, Projeto, Tecnologia, Verba); II) assunto (termos específicos); III) escala espacial (para avaliar a distribuição das matérias em nível local, regional, estadual, nacional ou global). Em seguida, utilizou-se o programa Origin 7.5, para análise gráfica e estatística dos resultados.

\section{RESULTADOS E DISCUSSÃO}

Os temas gerais mais abordados nas matérias de CT\&I dos periódicos avaliados foram, por ordem decrescente de frequência: I) tecnologia/tecnológico; II) projeto; III) dinheiro/recurso/verba; IV) pesquisa; V) programa; VI) desenvolvimento; VII) equipamento e VIII) ciência. A distribuição pode ser visualizada na Figura 1, a seguir. 


\section{Figura 1 - Gráfico dos termos gerais abordados nas matérias de CT\&I dos periódicos avaliados, em dez/2014.}

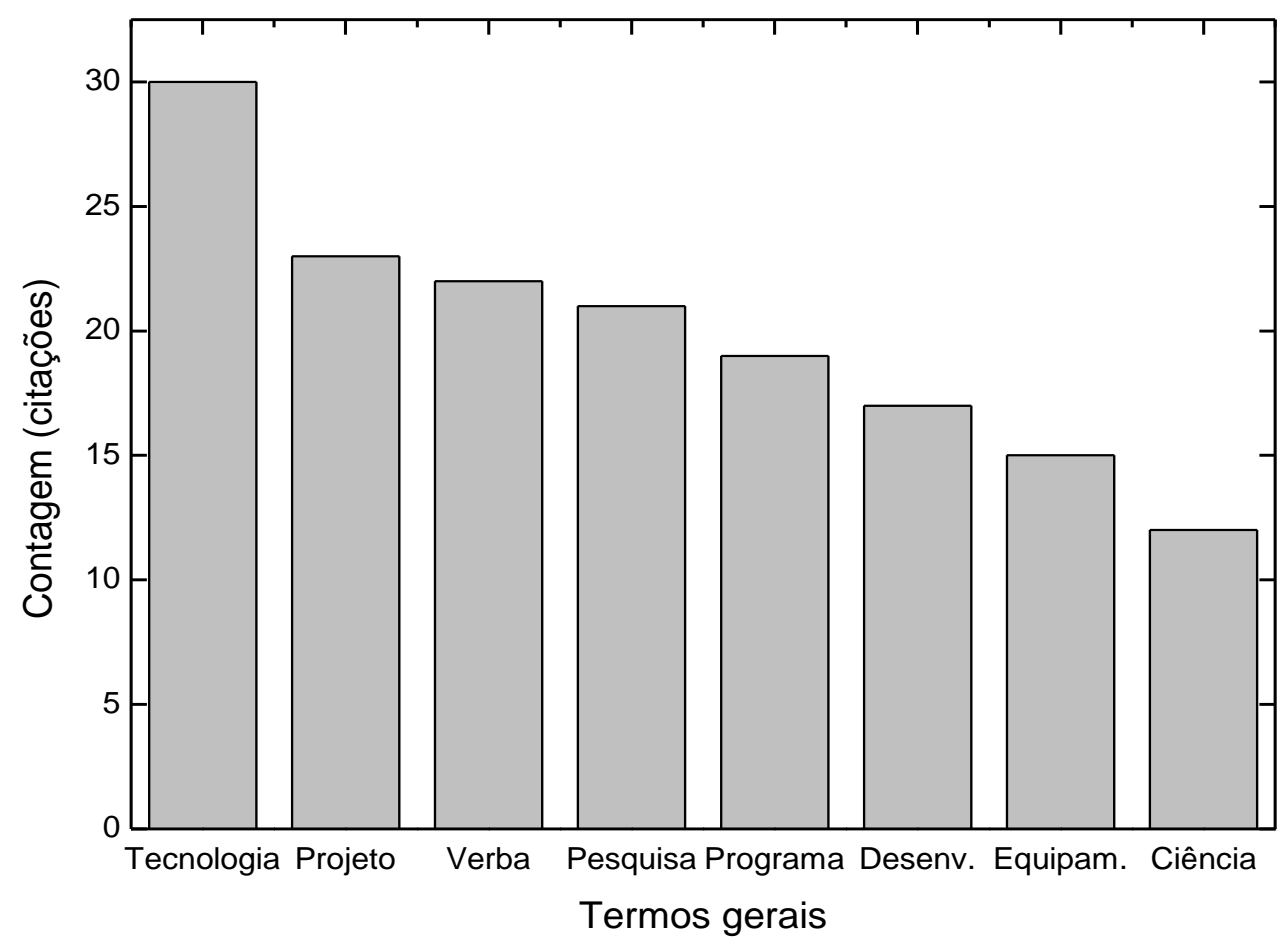

Fonte: Autor.

Observa-se a predominância de "tecnologia" e a presença, junto a termos especificamente ligados à CT\&I, dos termos "dinheiro/recurso/verba" (agrupados em "verba" no gráfico), cuja incidência conjunta é, basicamente, o dobro do registrado para a palavra "ciência". A partir dessa constatação, consideramos importante levantar algumas questões acerca do financiamento das atividades vinculadas à CT\&l em nosso país.

No Brasil, a maior parte do investimento científico apresenta origem governamental, tratando-se de verba pública; o financiamento da maioria das atividades de pesquisa fundamental deve-se a instituições públicas como o Conselho Nacional de Desenvolvimento Científico e Tecnológico (CNPq) e a fundações estaduais de amparo à pesquisa (como a Fundação de Amparo à Pesquisa do Estado de São Paulo - FAPESP, em São Paulo), vinculadas, respectivamente, ao governo federal e aos governos estaduais. Nesse sentido, justifica-se a importância atribuída pela imprensa (a julgar pela análise evidenciada por intermédio da Figura 1) ao termo geral "verba", que indicaria uma preocupação em relação ao investimento de dinheiro público.

No entanto, há que se considerar dois fatores:

I) A preocupação - por parte da imprensa - com a destinação de verbas públicas para a pesquisa não significa, necessariamente, atenção voltada para a ciência, inserindo-se, na verdade, dentro do contexto mais amplo (e necessário) de 
fiscalização acerca da utilização desses recursos;

II) Para que a população seja capaz de exercer democraticamente o direito de questionar e participar das decisões a respeito do gasto de verba pública, é necessário que essa mesma população esteja devidamente informada a respeito das atividades científicas específicas às quais é destinada tal verba, o que, muitas vezes, requer um aprofundamento não efetivado pela cobertura midiática.

Uma análise crítica sobre o (pouco) espaço dado à ciência, nos veículos avaliados, permite afirmar que, se é verdade que o jornalismo presta o serviço público de apresentar os gastos dos investimentos em CT\&l; por outro lado, falha ao apresentar esses dados de modo isolado, sem cumprir o papel de divulgar, adequadamente, e de modo continuado, as atividades científicas realizadas no país. Ao se omitir quanto à difusão de uma "cultura científica", que seria pré-requisito para que a população pudesse avaliar, criticamente, o investimento em CT\&I no Brasil, será que a imprensa não estaria contribuindo, inclusive, para uma visão negativa da ciência, que, potencialmente, passa a ser vista como algo que gera gastos públicos elevados, sem um retorno claro à população?

A esse respeito, Lage (2001) observa:

[...] A pouca divulgação da atividade científica brasileira, por exemplo, articula-se com uma representação de atraso que nem sempre corresponde à realidade do país, mas serve a objetivos políticos e institucionais claros. (LAGE, 2001, p. 122).

Passando aos assuntos (temas específicos) abordados nas matérias em questão, observa-se predominância absoluta do termo China-Brazil Earth-Resources Satellite (C BERS), que se refere ao satélite lançado pelo INPE, em parceria com a China (o lançamento ocorreu no dia 7 de dezembro de 2014, em território chinês). Em seguida e por ordem decrescente, aparecem, com destaque, os temas: satélite(s), espaço/espacial/espaciais, raios, saúde, internet, crimes, água, segurança e ambiental/ambiente. Fazendo um agrupamento de termos correlacionados (por exemplo, aqueles ligados ao contexto aeroespacial), elaborou-se a Figura 2. 
Figura 2 - Gráfico dos termos específicos mais citados nas matérias de CT\&I dos periódicos avaliados, em dez/2014.

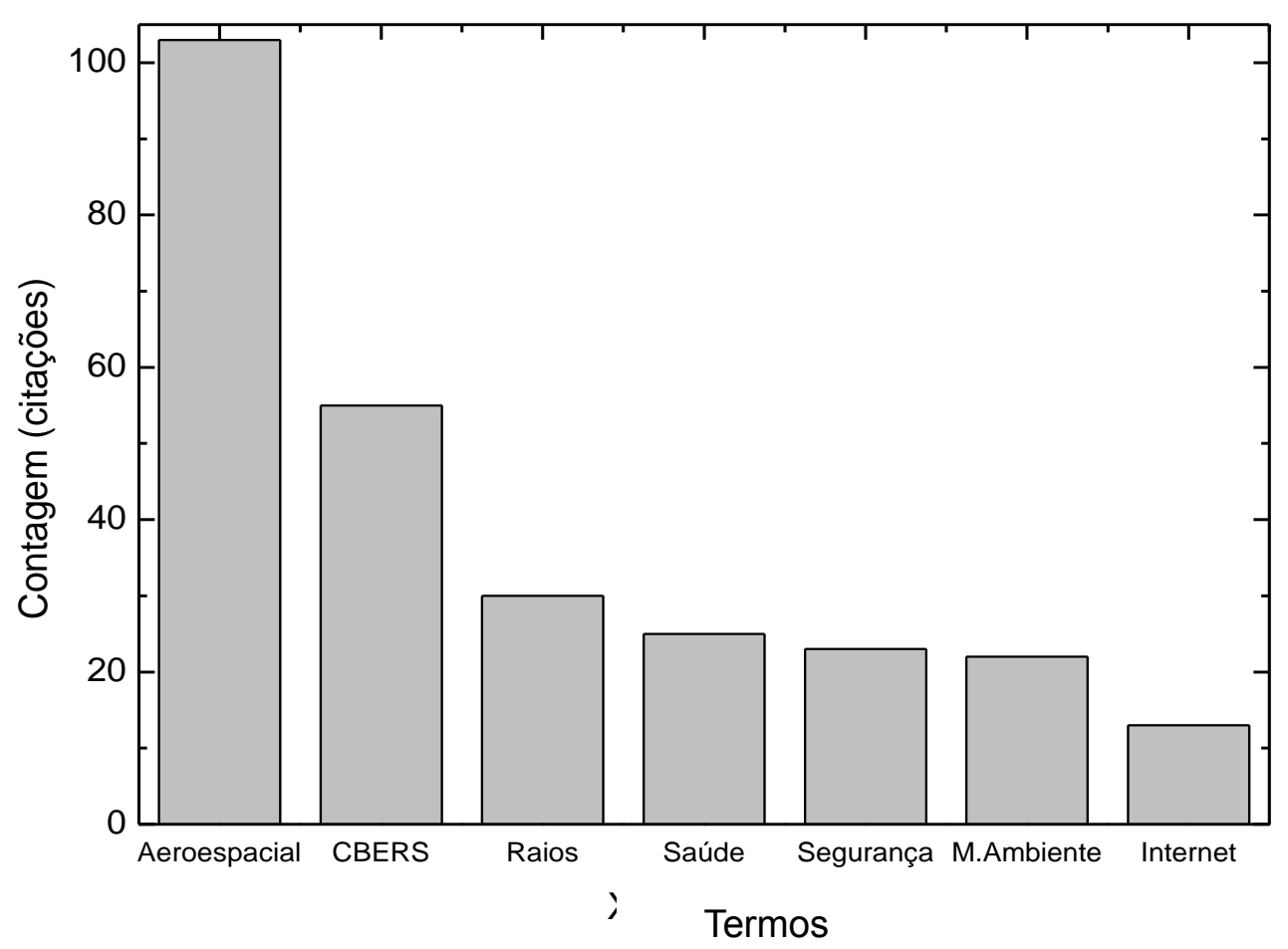

Fonte: Autor.

Os resultados, graficamente expressos, na figura 2 evidenciam que mais da metade de toda a cobertura de CT\&I, nesse período, esteve ligada ao contexto da pesquisa aeroespacial, com predominância do assunto CBERS. Em seguida, aparecem temas mais próximos do cotidiano, como "saúde", "segurança" e "meio ambiente".

Oliveira (2002) explica que a divulgação de atividades da área espacial chama a atenção das pessoas, por se tratar do "desconhecido" e por despertar uma das questões mais antigas da humanidade: de onde viemos? Essas atividades, assim, tendem a aparecer em matérias ligadas, especificamente, à tradicional Editoria de ciência. Por outro lado, os temas/questões de CT\&I que se mostrem mais próximos à vivência cotidiana da população podem ser explorados pelos jornalistas em editorias diversas, configurando-se como assuntos transversais:

A ciência ajuda a entender os fenômenos sociais e interpretar as causas e consequências dos fatos de interesse jornalístico. Se há alguma enchente, por exemplo, assunto que costuma ser divulgado na editoria de cidade ou na geral, o jornalista pode conversar com meteorologistas para entender o fenômeno natural. (OLIVEIRA, 2002, p. 46).

Quanto à meteorologia, especificamente, a presença recorrente desse tema na 
cobertura da imprensa local (frequentemente na seção Cidades) pode ser associada aos seguintes fatores:

I) A cidade de Caçapava (pertencente ao Vale do Paraíba) está entre as 10 cidades com maior incidência de raios no Estado de São Paulo;

II) O ELAT (Grupo de Eletricidade Atmosférica) é referência no tema raios e faz parte do INPE, em São José dos Campos.

Escala Espacial - No que se refere à escala espacial, as referências geográficas mais frequentes foram, com um mínimo de 10 citações cada e em ordem decrescente de número de ocorrências: São José dos Campos, Brasil, São Paulo, China (muito mencionada por conta de sua associação no CBERS), Vale do Paraíba e Taubaté. Avaliando-se o conjunto do material e classificando-se a distribuição das matérias conforme a escala espacial, obteve-se a seguinte divisão: escala local (município) com $19 \%$ de citações, escala regional (Vale do Paraíba) com $28 \%$, escala estadual com $16 \%$, escala nacional com $19 \%$ e escala global com $18 \%$, conforme pode ser visto na Figura 3, a seguir.

\section{Figura 3 - Gráfico da espacialização nas matérias de CT\&I dos periódicos avaliados, em dez/2014.}

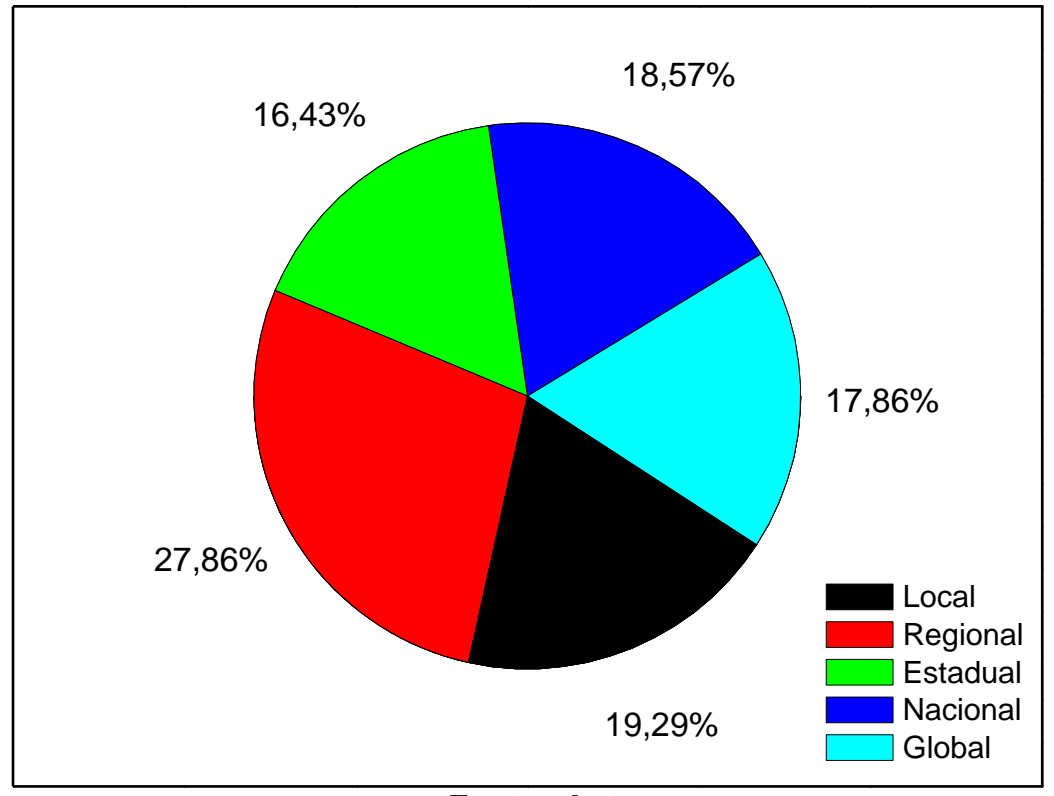

Fonte: Autor.

Observa-se quase a metade das matérias com espacialização em nível local/regional, o que diverge, significativamente, do estudo de Oliveira (2002), que afirma que as notícias de CT\&I apresentam caráter internacional, na maioria dos casos. Nesse sentido, o estudo efetuado parece apontar para uma peculiaridade regional que podemos atribuir a dois fatores: 
I) São José dos Campos configura-se como centro nacional no que se refere a pesquisas na área espacial e de tecnologia de aviação, dadas (principalmente) as presenças respectivas do INPE e da Empresa Brasileira de Aeronáutica (EMBRAER) na cidade;

II) Dezembro de 2014 marcou o lançamento do CBERS, empreendimento de grande porte e que, naturalmente, foi destaque não apenas na imprensa local. Esta, porém, enfatizou o fato de que São José dos Campos foi, em grande medida, o centro do desenvolvimento do projeto.

No que se refere às fontes e/ou instituições citadas nas matérias, encontra-se predominância absoluta de menções ao INPE (36 citações, basicamente por conta do lançamento do satélite CBERS, em dezembro e pela alta frequência de descargas elétricas atmosféricas no período), seguido por Companhia Ambiental do Estado de São Paulo - CETESB (5) e, com até três citações cada, Departamento de Ciência e Tecnologia Aeroespacial (DCTA), EMBRAER, Universidade Estadual Paulista (UNESP), Universidade Federal de Itajubá (UNIFEI) e Universidade do Vale do Paraíba (UNIVAP). Também aqui, portanto, é possível apontar uma ênfase da imprensa na produção de matérias envolvendo instituições diretamente vinculadas à região do Vale do Paraíba.

\section{CONCLUSÃO}

O presente estudo permite observar que dois dos principais veículos de informação no Vale do Paraíba (O Vale e Meon), durante o período analisado, apresentaram, em sua maioria, matérias referentes ou que consultavam fontes relacionadas ao instituto de pesquisa mais proeminente na região, o INPE. Comprovamos isso ao observar que as três maiores ocorrências de temas específicos (aeroespacial, CBERS e raios) aparecem, invariavelmente, relacionadas ao referido instituto. Um ponto de destaque evidente é a grande ocorrência de "movimentação científica" no INPE, associada ao lançamento do CBERS; vale observar, também, que o mês de dezembro corresponde ao período de aumento de incidência de descargas atmosféricas ("raios"), e que a região do Vale do Paraíba é bastante atingida por essas descargas.

Foi possível observar uma homogeneidade entre os veículos avaliados no presente estudo. Bourdieu (2001) apresenta postura crítica a esse respeito, apontando esse caráter homogêneo dos jornais, com jornalistas disputando, entre si, as notícias (inclusive lendo o material publicado pelo concorrente, para garantir que, também, publiquem sobre o assunto). Isso ocorreu na cobertura de CT\&I, do período avaliado: os jornais, basicamente, reproduziram as mesmas notícias, majoritariamente, sobre os temas CBERS e descargas atmosféricas. Além disso, as matérias avaliadas evidenciam redação efetuada, muitas vezes, a partir de releases, não explorando 
diversidade de aspectos e temas. Lembramos que o presente trabalho se insere no contexto mais amplo de pesquisa, em andamento no LabCom Univap, sobre divulgação científica e seu impacto na sociedade na região do Vale do Paraíb. Desse modo, espera-se aprofundar esta análise em trabalhos futuros, ampliando, por exemplo, a janela temporal de pesquisa.

\section{REFERÊNCIAS}

ALBAGLI, S. Divulgação Científica: informação científica para a cidadania? Ci. Inf., Brasília. v. 25, n. 3, p. 396-404. 1996.

BOURDIEU, P. Sobre a televisão. Rio de Janeiro: Jorge Zahar Editora, 2001.

LAGE, N. A Reportagem. São Paulo: Editora Record, 2001.

OLIVEIRA, F. Jornalismo Científico. São Paulo: Editora Contexto, 2002.

SILVA, G; AROUCA, M; GUIMARÃES, V. As exposições de divulgação da ciência. In: MASSARANI, L.; MOREIRA, I; BRITO, F. Ciência e Público: caminhos da divulgação científica no Brasil. Rio de Janeiro: Casa da Ciência, 2002. 